\title{
Aurovertin E, a New Polyene Pyrone from the Basidiomycete Albatrellus confluens
}

\author{
Fei Wang, Du-Qiang Luo, Ji-Kai Liu
}

Received: April 8, 2005 / Accepted: May 31, 2005

(C) Japan Antibiotics Research Association

\begin{abstract}
A new polyene pyrone, aurovertin E (2), was isolated along with aurovertin B (1) from the culture mycelia of the basidiomycete Albatrellus confluens. Their structures were elucidated on the basis of spectroscopic studies including 2D NMR experiments. This is the first example of the occurrence of aurovertins in basidiomycetes.
\end{abstract}

Keywords aurovertin E, Albatrellus confluens, basidiomycete, polyene pyrone

\section{Introduction}

The aurovertins, metabolites from the fungus (anamorphic ascomycetes) Calcarisporium arbuscula Preuss [1 4], are a group of acute neurotoxic substances which act as potent inhibitors of ATP synthesis and ATP hydrolysis catalyzed by mitochondrial enzyme systems $[5,6]$. It was also reported that aurovertin $\mathrm{B}$ is a bovine $\mathrm{F}_{1}$-ATPase inhibitor [7]. The sites at which aurovertin $B$ binds to bovine $F_{1-}$ ATPase have been determined by X-ray analysis of crystals soaked in the inhibitor. Aurovertin B has been totally synthesized from D-glucose and its absolute configuration has been unambiguously determined [8, 9]. The biosynthetic origins of the aurovertins have also been reported $[10,11]$. In a continuation of our investigation of the bioactive principles from the fungus (basidiomycetes) Albatrellus confluens (Alb. et Schw.: Fr.) Kolt. et Pouz. [12 15], a new polyene pyrone, aurovertin E (2), was isolated along with aurovertin B (1) from its culture

J.-K. Liu (Corresponding author), F. Wang, D.-Q. Luo: Kunming Institute of Botany, the Chinese Academy of Sciences, Kunming 650204, China,E-mail: jkliu@mail.kib.ac.cn mycelia. We describe herein the isolation and structural elucidation of aurovertin E (2).

\section{Experimental}

\section{General}

Optical rotations were measured on a Horiba SEPA-300 polarimeter. IR spectra were obtained with a Tensor 27 with $\mathrm{KBr}$ pellets. UV spectra were recorded on a Shimadzu UV2401PC spectrophotometer. NMR spectra were recorded on Bruker AV-400 and Bruker DRX-500 spectrometers in $\mathrm{CDCl}_{3}$ solvent with TMS as an internal standard. EI-MS were recorded with a VG Autospec-3000 spectrometer. ESI-MS and HRESI-MS were recorded with an API QSTAR Pulsar 1 spectrometer.

Silica gel (200 300 mesh, Qingdao Marine Chemical Inc., China) and Sephadex LH-20 (Amersham Biosciences, Sweden) were used for column chromatography. Fractions were monitored by TLC and spots were visualized by heating silica gel plates sprayed with $10 \% \mathrm{H}_{2} \mathrm{SO}_{4}$ in ethanol.

\section{Fermentation and Isolation}

The mushroom A. confluens was collected at Ailao Mountain of Yunnan Province, China, in July 2003 and identified by Prof. Zang Mu, Kunming Institute of Botany, the Chinese Academy of Sciences. The voucher specimen was deposited in the Herbarium of Kunming Institute of Botany, the Chinese Academy of Sciences.

The culture medium consisted of potato (peel off) $200 \mathrm{~g}$,

F. Wang: Graduate School of the Chinese Academy of Sciences, Beijing 100039, China 
glucose $20 \mathrm{~g}, \mathrm{KH}_{2} \mathrm{PO}_{4} 3 \mathrm{~g}, \mathrm{MgSO}_{4} 1.5 \mathrm{~g}$, citric acid $0.1 \mathrm{~g}$ and thiamin hydrochloride $10 \mathrm{mg}$ in 1 liter of deionized water. Reagent bottles were used as flask (size: $500 \mathrm{ml}$; volume of media: $300 \mathrm{ml}$ ). The $\mathrm{pH}$ was adjusted to 6.5 before autoclaving. Fermentation was carried out on a shaker at $22^{\circ} \mathrm{C}$ and $150 \mathrm{rpm}$ for 10 days.

The 10-day old whole culture broth (12 liters) was filtered and then extracted twice with EtOAc. The organic layer was concentrated in vacuo to give an oily residue $(1.1 \mathrm{~g})$ that was applied on a silica gel column and eluted stepwise with $\mathrm{CHCl}_{3}-\mathrm{MeOH}$ solvent system. Fr. I (18 mg), eluted with $\mathrm{CHCl}_{3}-\mathrm{MeOH}(100: 1, \mathrm{v} / \mathrm{v})$, was further purified on a Sephadex LH-20 column, eluting with $\mathrm{CHCl}_{3}-\mathrm{MeOH}(1: 1, \mathrm{v} / \mathrm{v})$ to give $\mathbf{1}(2.3 \mathrm{mg})$ as a pale yellow syrup. Fr. II (24 mg) from $\mathrm{CHCl}_{3}-\mathrm{MeOH}(60: 1$, $\mathrm{v} / \mathrm{v}$ ) was repeatedly purified on a Sephadex LH-20 column, eluting with $\mathrm{CHCl}_{3}-\mathrm{MeOH}(1: 1, \mathrm{v} / \mathrm{v})$, to afford 2 (2.9 mg) as a pale yellow syrup.

\section{Physico-chemical Properties}

Aurovertin B (6-[(1E,3E,5E)-6-[8-acetyloxy-7-ethyl-4hydroxy-1,5-dimethyl-2,6-dioxabicyclo[3.2.1] oct-3-yl]1,3,5-hexatrienyl]-4-methoxy-5-methyl-2 $\mathrm{H}$-pyran-2-one, 1). Pale yellow syrup, $[\alpha]_{\mathrm{D}}^{16.4}-25.3\left(c 0.47, \mathrm{CHCl}_{3}\right)$, $\mathrm{Rf}=$ 0.76, $\mathrm{CHCl}_{3}-\mathrm{MeOH}, 12: 1$ (v/v). EI-MS $m / z 460$ (M, 2), $442\left(\mathrm{M}-\mathrm{H}_{2} \mathrm{O}, 5\right), 418\left(\mathrm{M}-\mathrm{CH}_{2} \mathrm{CO}, 2\right), 400(\mathrm{M}-$ $\mathrm{H}_{2} \mathrm{O}-\mathrm{CH}_{2} \mathrm{CO}, 2$ ), 341 (5), 325 (15), 302 (14), 247 (29), 219 (67), 109 (41).

Aurovertin E (6-[(1E,3E,5E)-6-[4,8-dihydroxy-7-ethyl1,5-dimethyl-2,6-dioxabicyclo[3.2.1]oct-3-yl]-1,3,5hexatrienyl]-4-methoxy-5-methyl-2H-pyran-2-one, 2). Pale yellow syrup, $[\alpha]_{\mathrm{D}}^{17.2}-14.1\left(c 0.59, \mathrm{CHCl}_{3}\right), \mathrm{Rf}=0.43$, $\mathrm{CHCl}_{3}-\mathrm{MeOH}, 12: 1 \quad(\mathrm{v} / \mathrm{v})$. UV $\lambda_{\max }^{\mathrm{CHCl}_{3}} \mathrm{~nm}(\varepsilon) 370$ $(34,400), 360$ (sh), 277 (34,800), 270 (33,300). IR (KBr) 3432, 2956, 2919, 2850, 1682, 1623, 1539, 1462, 1406, 1378, 1251, 1092, 1037, 1002, $972 \mathrm{~cm}^{-1}$. ESI-MS m/z 419 $(\mathrm{M}+1)^{+}, 441(\mathrm{M}+\mathrm{Na})^{+}, 859(2 \mathrm{M}+\mathrm{Na})^{+}$. HRESI-MS $\mathrm{m} / \mathrm{z}$ 419.2054 (M+1, Calcd. for $\left.\mathrm{C}_{23} \mathrm{H}_{31} \mathrm{O}_{7} 419.2069\right)$. EI-MS m/z 418 (M, 3), $400\left(\mathrm{M}-\mathrm{H}_{2} \mathrm{O}, 7\right), 341$ (5), 325 (9), 302

Table $1{ }^{1} \mathrm{H}$ and ${ }^{13} \mathrm{C}$ NMR data for $\mathbf{1}$ and $\mathbf{2}$ in $\mathrm{CDCl}_{3}$.

\begin{tabular}{|c|c|c|c|c|}
\hline Position & 1 & & 2 & \\
\hline 1 & $1.10(3 \mathrm{H}, \mathrm{t}, 7.5)$ & 11.8 & $1.08(3 \mathrm{H}, \mathrm{t}, 7.5)$ & 11.9 \\
\hline 2 & $1.70(2 \mathrm{H}, \mathrm{m})$ & 20.1 & $1.68(2 \mathrm{H}, \mathrm{m})$ & 20.2 \\
\hline 3 & $3.93(1 \mathrm{H}, \mathrm{dd}, 8.8,4.3)$ & 85.5 & $3.97(1 \mathrm{H}, \mathrm{dd}, 8.7,4.5)$ & 84.8 \\
\hline 4 & & 82.7 & & 83.6 \\
\hline 5 & $4.81(1 \mathrm{H}, \mathrm{s})$ & 80.5 & $3.46(1 \mathrm{H}, \mathrm{s})$ & 80.4 \\
\hline 6 & & 83.4 & & 84.1 \\
\hline 7 & $3.29(1 \mathrm{H}, \mathrm{d}, 8.2)$ & 76.3 & $3.17(1 \mathrm{H}, \mathrm{d}, 8.1)$ & 76.3 \\
\hline 8 & $4.13(1 \mathrm{H}, \mathrm{dd}, 8.2,6.1)$ & 78.0 & $4.13(1 \mathrm{H}, \mathrm{dd}, 8.1,6.3)$ & 77.9 \\
\hline 9 & $5.93(1 \mathrm{H}, \mathrm{dd}, 14.2,6.1)$ & 134.0 & $5.91(1 \mathrm{H}, \mathrm{dd}, 14.2,6.3)$ & 134.7 \\
\hline 10 & a & 131.8 & b & 131.6 \\
\hline 11 & a & 137.0 & b & 137.2 \\
\hline 12 & a & 132.1 & $\mathrm{~b}$ & 131.9 \\
\hline 13 & $7.19(1 \mathrm{H}, \mathrm{dd}, 15.0,11.2)$ & 135.6 & $7.18(1 \mathrm{H}, \mathrm{dd}, 15.0,11.2)$ & 135.7 \\
\hline 14 & $6.36(1 \mathrm{H}, \mathrm{d}, 15.0)$ & 119.6 & $6.35(1 \mathrm{H}, \mathrm{d}, 15.0)$ & 119.4 \\
\hline 15 & & 154.2 & & 154.3 \\
\hline 16 & & 108.1 & & 108.1 \\
\hline 17 & & 170.6 & & 170.6 \\
\hline 18 & $5.50(1 \mathrm{H}, \mathrm{s})$ & 88.8 & $5.50(1 \mathrm{H}, \mathrm{s})$ & 88.8 \\
\hline 19 & & 163.8 & & 163.8 \\
\hline 20 & $1.19(3 \mathrm{H}, \mathrm{s})$ & 16.4 & $1.29(3 \mathrm{H}, \mathrm{s})$ & 16.4 \\
\hline 21 & $1.27(3 \mathrm{H}, \mathrm{s})$ & 15.0 & $1.38(3 \mathrm{H}, \mathrm{s})$ & 14.6 \\
\hline 22 & $1.97(3 \mathrm{H}, \mathrm{s})$ & 8.9 & $1.97(3 \mathrm{H}, \mathrm{s})$ & 8.9 \\
\hline 23 & $3.83(3 \mathrm{H}, \mathrm{s})$ & 56.2 & $3.83(3 \mathrm{H}, \mathrm{s})$ & 56.2 \\
\hline $\mathrm{COCH}_{3}$ & $2.17(3 \mathrm{H}, \mathrm{s})$ & 20.8 & & \\
\hline $\mathrm{COCH}_{3}$ & & 169.9 & & \\
\hline
\end{tabular}

a,b Complex signals $\delta 6.35 \sim 6.55$.

Assignments made on the basis of ${ }^{1} \mathrm{H},{ }^{1} \mathrm{H}-\mathrm{COSY}, \mathrm{HSQC}$ and $\mathrm{HMBC}$ experiments. 
(28), 259 (16), 247 (35), 219 (57), 218 (80), 139 (100).

\section{Results and Discussion}

Compound 2 was obtained as yellow syrup. The molecular formula of 2 was determined to be $\mathrm{C}_{23} \mathrm{H}_{30} \mathrm{O}_{7}$ on the basis of HRESI-MS $m / z 419.2054\left(\mathrm{M}+1\right.$, calcd. for $\mathrm{C}_{23} \mathrm{H}_{31} \mathrm{O}_{7}$ 419.2069) and ${ }^{13} \mathrm{C}$ NMR spectrum (DEPT: five methyls, one methylene, eleven methines and six quaternary carbons). The IR spectra of $\mathbf{2}$ showed absorptions at 1682, 1623 and $1539 \mathrm{~cm}^{-1}$ consistent with the presence of a 4oxy- $\alpha$-pyrone unit and at $3432(\mathrm{br}, \mathrm{OH}) \mathrm{cm}^{-1}$. The ${ }^{1} \mathrm{H}$ and ${ }^{13} \mathrm{C}$ NMR spectra (Table 1) of 2 were similar to those of aurovertin B (1) $[3,11]$. The distinct differences between compound 2 and aurovertin B (1) are that: (a) the acetyl signals of aurovertin $\mathrm{B}\left[\delta_{\mathrm{H}} 2.17(3 \mathrm{H}, \mathrm{s}), \delta_{\mathrm{C}} 20.8(\mathrm{q}, \mathrm{Me})\right.$ and $169.9(\mathrm{~s}, \mathrm{C}=\mathrm{O})$ ] are absent in 2; (b) a characteristic downfield singlet $\left[\delta_{\mathrm{H}} 4.81(1 \mathrm{H}, \mathrm{s})\right]$ caused by esterification is markedly shifted upfield $\left[\delta_{\mathrm{H}} 3.46(1 \mathrm{H}, \mathrm{s})\right]$ in $\mathbf{2}$. In the light of the evidences mentioned above and the key HMBC correlations (Fig. 2), the structure of $\mathbf{2}$ was therefore elucidated as shown in Fig. 1, named aurovertin E. Because the NMR spectral data and other physico-chemical properties of $\mathbf{2}$ and those of $\mathbf{1}$ in literature are very similar, the absolute configuration and geometrical isomerism of both compounds are suggested to be the same.

The molecule consists of a substituted pyrone ring linked

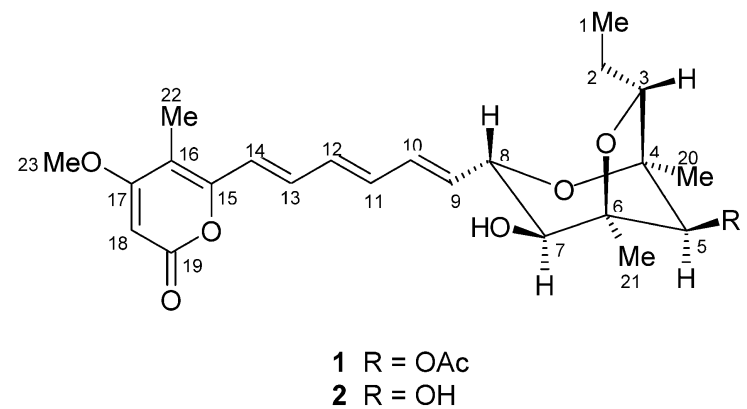

Fig. 1 Structures of $\mathbf{1}$ and $\mathbf{2}$.

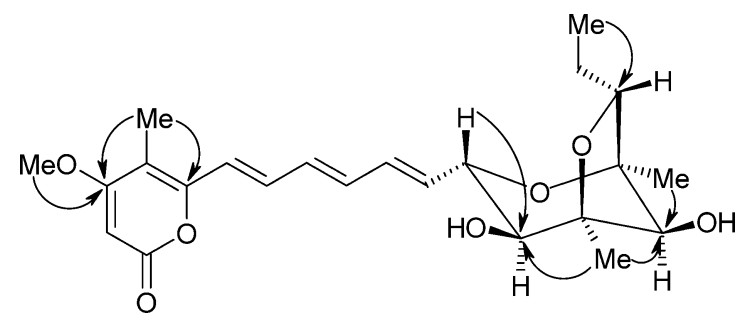

Fig. 2 Key HMBC correlations of 2. by a rigid spacer containing conjugated double bonds to a substituted dioxabicyclo[3.2.1]octane. It is important to note that this is the first isolation of the aurovertins from basidiomycetes.

Aurovertin E (2) has been mentioned as a product of the reaction from aurovertin B (1) by alkaline hydrolysis [3]. It is of interest if aurovertin $\mathrm{E}$ that is the deacetylated derivative of $\mathbf{1}$ has a $\mathrm{F}_{1}$-ATPase inhibiting activity as $\mathbf{1}$.

Acknowledgements This project was supported by the National Natural Science Foundation of China (30470027 and 30225048).

\section{References}

1. Baldwin CL, Weaver LC, Brooker RM, Jacobsen TN, Osborne CE, Jr., Nash HA. Biological and chemical properties of aurovertin, a metabolic product of Calcarisporium abuscula. Lloydia 27: 88-95 (1964)

2. Osselton MD, Baum H, Beechey RB. Isolation, purification and characterization of aurovertin B. Biochem Soc Trans 2: 200-202 (1974)

3. Mulheirn LJ, Beechey RB, Leworthy DP, Osselton MD. Aurovertin B, a metabolite of Calcarisporium arbuscula. J Chem Soc, Chem Commun 1974: 874-876 (1974)

4. Linnett PE, Beechey RB. Inhibitors of the ATP synthetase systems. Methods Enzymol 55: 472-518 (1979)

5. Lardy HA, Connelly JL, Johnson D. Antibiotics as tools for metabolic studies. II. Inhibition of phosphoryl transfer in mitochondria by oligomycin and aurovertin. Biochemistry 3 : 1961-1968 (1964)

6. Roberton AM, Beechey RB, Holloway CT, Knight IG, The effect of aurovertin on a soluble mitochondrial adenosine triphosphatase. Biochem J 104: 54C-55C (1967)

7. van Raaij MJ, Abrahams JP, Leslie AGW, Walker JE. The structure of bovine $\mathrm{F}_{1}$-ATPase complexed with the antibiotic inhibitor aurovertin B. Proc Natl Acad. Sci USA 95: 69136917 (1996)

8. Nishiyama S, Toshima H, Kanai H, Yamamura S. Total synthesis and the absolute configuration of aurovertin B. Tetrahedron Lett 27: 3643-3646 (1986)

9. Nishiyama S, Toshima H, Kanai H, Yamamura S. Total synthesis and the absolute configuration of aurovertin B, an acute neurotoxic metabolite. Tetrahedron 44: 6315-6324 (1988)

10. Steyn PS, Vleggaar R, Wessels PL. Biosynthesis of aurovertin $\mathrm{B}$. The role of methionine in the formation of ethyl side-chain. J Chem Soc, Chem Commun 1979: 10411042 (1979)

11. Steyn PS, Vleggaar R, Wessels PL. Biosynthesis of the aurovertins $\mathrm{B}$ and $\mathrm{D}$. The role of methionine and propionate in the simultaneous operation of two independent biosynthetic pathways. J Chem Soc, Perkin I 1981: 1298- 
1308 (1981)

12. Ding ZH, Dong ZJ, Liu JK. Albaconol, a novel prenylated resorcinol (=benzene-1,3-diol) from basidiomycetes Albatrellus confluens. Helv Chim Acta 84: 259-262 (2001)

13. Yang WM, Liu JK, Qing C, Liu YD, Ding ZH, Shen ZQ, Chen ZH. Albaconol from the mushroom Albatrellus confluens induces contraction and desensitization in guinea pig trachea. Planta Med 69: 715-719 (2003)

14. Qing C, Liu MH, Yang WM, Zhang YL, Wang L, Liu JK.
Effects of albaconol from the basidiomycete Albatrellus confluens on DNA topoisomerase II-mediated DNA cleavage and relaxation. Planta Med 70: 792-796 (2004)

15. Hellwig V, Nopper R, Mauler F, Freitag J, Liu JK, Ding ZH, Stadler M. Activities of prenylphenol derivatives from fruitbodies of Albatrellus spp. on the human and rat vanilloid receptor 1 (VR1) and characterisation of the novel natural product, confluentin. Arch Pharm Pharm Med Chem 2: 119-126 (2003) 